\title{
Malignant Hyperthermia: Evaluation of “Organon" 9426 in Malignant Hyperthermia Susceptible Pigs
}

\author{
Charles H. Williams \\ The Williams Research Laboratories, Sunrise Beach, USA \\ Email: chwilliams2135@sbcglobal.net
}

Received 10 April 2015; accepted 24 May 2015; published 27 May 2015

Copyright (C) 2015 by author and Scientific Research Publishing Inc.

This work is licensed under the Creative Commons Attribution International License (CC BY).

http://creativecommons.org/licenses/by/4.0/

(c) (i) Open Access

\begin{abstract}
Control pigs required $109.9 \mathrm{ug} / \mathrm{kg} / \mathrm{min}$ and MHS pigs required $72.4 \mathrm{ug} / \mathrm{kg} / \mathrm{min}$ infusion of $\mathrm{Orga}$ non 9426 to maintain a $90 \%$ block. It appears that Organon 9426 is only one-third to one-half as potent as Vecuronium in pigs. The fact that MHS pigs only require $66 \%$ of the infusion dose to maintain a $90 \%$ block suggests that there is difference in the neuromuscular effect of Organon 9426 in MHS vs. control pigs. A linear regression analysis of the dose response data to Organon 9426 in MHS pigs indicated that $427.033 \mathrm{ug} / \mathrm{kg}$ would be required to produce a $100 \%$ neuromuscular blockade vs. $586.31 \mathrm{ug} / \mathrm{kg}$ in control pigs. Nine of the ten MHS pigs did not develop MH or show any signs of impending MH during the halothane and succinylcholine challenge at the end of the infusion period. Organon 9426 is the first muscle relaxant to offer significant protective action at a clinical dose. This suggests that there is an allosteric site on the sodium channel (acetylcholine receptor) which regulates the flow of sodium ions through the sodium channel. Organon 9426 may be therapeutically effective in an active MH case [1].
\end{abstract}

\section{Keywords}

Malignant Hyperthermia, Organon 9426, Neuromuscular Disease

\section{Introduction}

We have evaluated several new muscle relaxants in MHS pigs as the animal experimental phase of new drug development [2]-[9]. Also, we have evaluated several old muscle relaxants as part of our research program to elucidate the triggering mechanism which initiates $\mathrm{MH}[10]-[13]$.

This paper reports the data and results we have obtained on ORG 9426 which is now on the market as Rocuronium.

How to cite this paper: Williams, C.H. (2015) Malignant Hyperthermia: Evaluation of "Organon" 9426 in Malignant Hyperthermia Susceptible Pigs. Open Journal of Molecular and Integrative Physiology, 5, 29-36. 
These studies were designed to evaluate the dose response of each pig, the continuous infusion dose required to maintain a $90 \%$ neuromuscular block and then to evaluate the $\mathrm{MH}$ triggering or prevention potential of ORG 9426.

\section{Methods and Materials}

Organon 9426 was supplied by Organon Inc. as $10 \mathrm{ml}$ vial, Lot \# OR.01.891C3 and Lot \# OR.04.89IC4 at a concentration of $20.0 \mathrm{mg} / \mathrm{ml}$.

The 10 MHS pigs were derived from our MHS breeding colony (see Figure 1) that was established in January 1969 [8] [14] [15]. The control pigs were commercial white pigs purchased from Paso Pork (Skov Farms) who maintained a breeding herd of 500 sows. The MHS pigs used in this series of experiments were classified as 3/4 hot based on a reaction to halothane challenge of 10 - 12 minutes.

The experiments were conducted in our animal research facilities at TTUHSC-El Paso. We used an HP-8 channel physiography, Model T158B, Edwards Model $9520 \mathrm{CO}$ computer, Marquette Electronics $\mathrm{CO}_{2}$ analyzer, Ohio Model 2000 anesthesia machine, Harvard Model 618 piston ventilator, Oximetric 02 analyzer with Opticath catheters, a Grass FTI0 force displacement transducer and HSE Model 359A neuromuscular monitor. Blood gases were run in the Thomason Hospital laboratory.

The animals were restrained with a snout holder, an intravenous line inserted into an ear vein and $30 \mathrm{ml}$ of Thiopental $(5 \mathrm{mg} / \mathrm{ml})$ was given for sedation. The animals were intubated and ventilated. Sterile surgical cutdowns were completed on the neck and inner thigh. The Opticath Swan-Ganz catheter was inserted into the jugular vein and advanced to the wedge position in the pulmonary artery. The internal carotid was catherized with a Millar Mikro-tip catheter pressure transducer and advanced to the apex of the left ventricle. The femoral artery was cut down and a $16 \mathrm{G}$ catheter was inserted retrograde $10-12 \mathrm{~cm}$ until a good arterial wave was recorded. Blood samples were collected at timed intervals for blood gas analyses.

Neuromuscular transmission was assessed by recording evoked twitch tension in response to a supramaximal train of four of the left peroneal nerve via needle electrode. The infusion of ORG 9426 was adjusted to provide a 90-95\% blocking dose after single dose response tests were completed (see Figure 2).

\section{Recording of Experimental DATA}

A 30 minute control period at a core temperature of $37-38 \mathrm{C}$ was recorded, blood gases were measured and duplicated cardiac output readings were recorded.

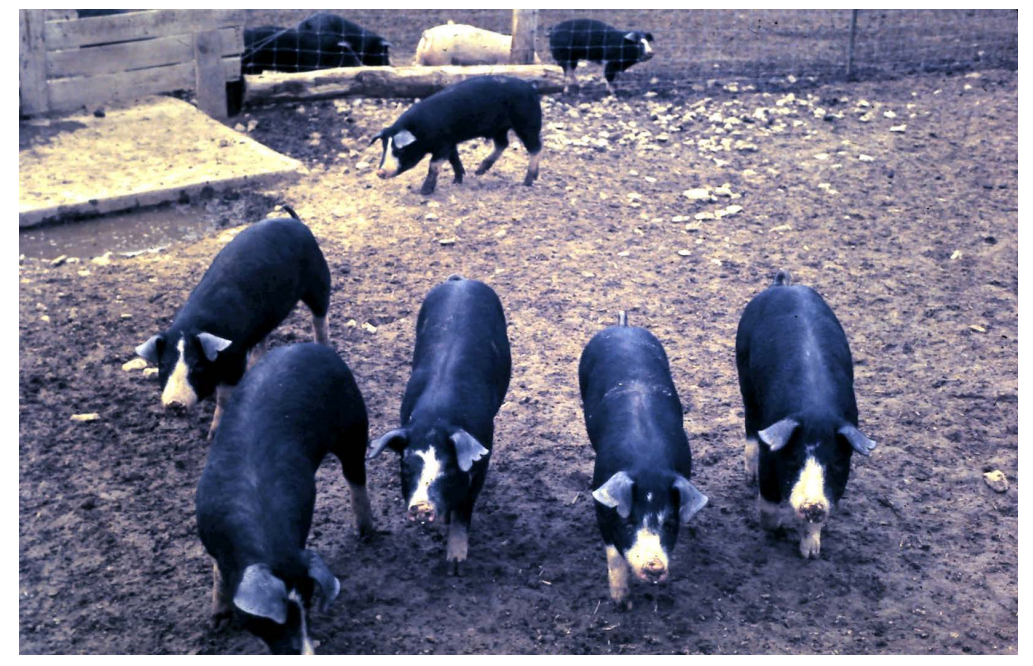

Figure 1. MHS pigs in the MHS pig colony at the farm. There is a considerable variation in response to the halothane challenge test so a breeding herd has to be established to identify those animals that are highly susceptible and that die from stress imposed by breeding activity, transport stress, and heat stress. We have been fortunate to be able to study the highly stress susceptible animals under laboratory conditions. 


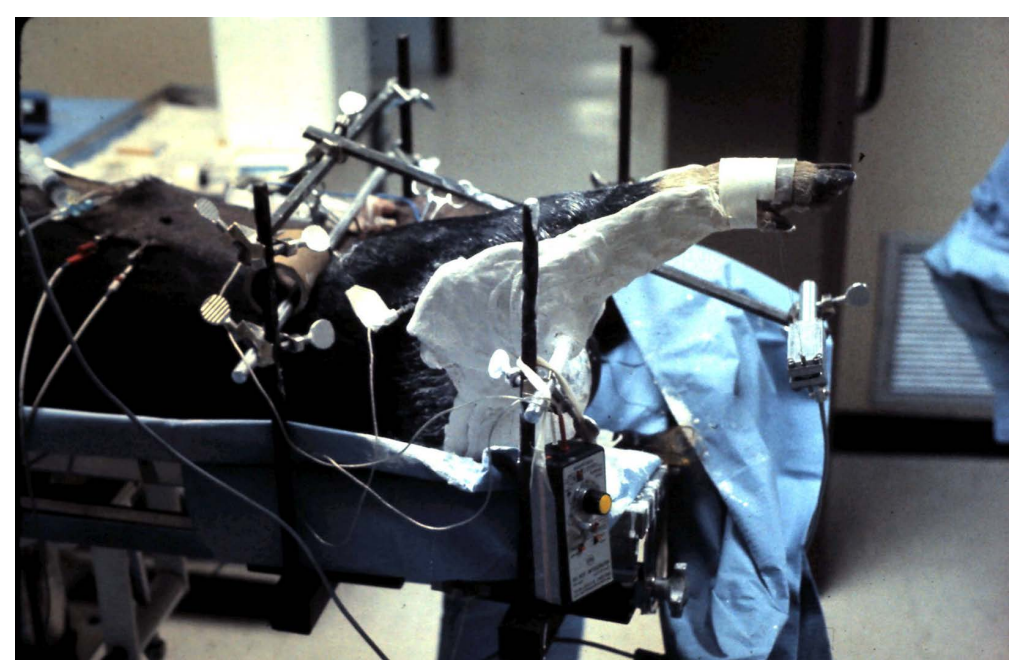

Figure 2. The experimental setup for recording neuromuscular blockade and twitch response with Organon 9426.

The pending development of $\mathrm{MH}$ was determined by:

1) Decrease of venous $\mathrm{pO}_{2}$ saturation to $60 \%$ or lower.

2) Core temperature $<39 \mathrm{C}$ or higher (0.1 C per min).

3) Muscle rigor.

4) End tidal $\mathrm{pCO}_{2}$ of 55 torr at STP.

5) Tachycardia +10 bpm increase over baseline.

\begin{tabular}{|c|c|c|c|c|c|c|}
\hline $30 \mathrm{~min}$ & Control & $\begin{array}{c}\text { Dose response } \\
\text { infusion } 2 \mathrm{hr}\end{array}$ & Acidosis $30 \mathrm{~min}$ & Alkalosis $30 \mathrm{~min}$ & $\begin{array}{c}\text { Halothane } 30 \\
\text { min }\end{array}$ & $\mathrm{SC}$ \\
\hline
\end{tabular}

\section{Dose Response Testing}

Pigs used on the ORG 9426 project:

8 control pigs with mean wt. $53.55 \mathrm{~kg}$;

$10 \mathrm{MH}$ pigs with mean wt. $50.93 \mathrm{~kg}$.

\section{Discussion}

ORG 9426 had an onset time of 45.6 see in control pigs and an onset time of $83.4 \mathrm{sec}$ in MHS pigs (see Figure 3). These onset times compare very favorably with $67.5 \mathrm{sec}$ in control pigs and $72.86 \mathrm{sec}$ in MHS pigs for pipecurium $\left(\right.$ Arduan $\left.^{R}\right)$ [11]. Onset time was $120 \mathrm{sec}$ in Tibialis and $174 \mathrm{sec}$ in Soleus muscles of the anesthetized cat [2]. Onset time was $108 \mathrm{sec}$ in Tibialis and $186 \mathrm{sec}$ in Soleus muscles of anesthetized pigs [2]. The onset time was $108 \mathrm{sec}$ in rats and $132 \mathrm{sec}$ in guinea pigs [3]. Onset times for ORG 9426 were not reported for human patients.

Duration 90 for ORG 9426 was 7.21 min in control pigs and 12.0 min in MHS pigs. Duration 90 was 10.5 $\mathrm{min}$ in control pigs and $8.93 \mathrm{~min}$ in MHS pigs used in the pipecurium (Arduan ${ }^{\mathrm{R}}$ ) experiments [11]. Clinical duration was $6 \mathrm{~min}$ in rats and $15.8 \mathrm{~min}$ in guinea pigs [3]. Clinical duration was $15.1 \mathrm{~min}$ in human patients. The duration 90 of ORG 9426 appears to be shorter in pigs than in humans.

$25 \%$ to $75 \%$ recovery rate was $2.84 \mathrm{~min}$ in control pigs and $4.59 \mathrm{~min}$ in MHS pigs. This compares favorably with $8.5 \mathrm{~min}$ for atracurium in pigs [11], $12.0 \mathrm{~min}$ for vecuronium in pigs [7], $4.36 \mathrm{~min}$ for pipecurium $\left(\right.$ Arduan $^{\mathrm{R}}$ ) in pigs, and $2.9 \mathrm{~min}$ for Tibialis and $5.2 \mathrm{~min}$ for Soleus muscles in the anesthetized cat [2]. The recovery rate was $2.1 \mathrm{~min}$ in rats and $5.3 \mathrm{~min}$ in guinea pigs. Our data is very comparable to $3.3 \mathrm{~min}$ for Tibialis and $5.7 \mathrm{~min}$ for Soleus muscles in the anesthetized pig [2].

Control pigs required $109.9 \mathrm{ug} / \mathrm{kg} / \mathrm{min}$ and MHS pigs required $72.4 \mathrm{ug} / \mathrm{kg} / \mathrm{rnin}$ infusion of ORG 9426 to maintain a 90 block. This contrasts with the $5.35 \mathrm{ug} / \mathrm{kg} / \mathrm{min}$ and $5.94 \mathrm{ug} / \mathrm{kg} / \mathrm{min}$ for control and MHS pigs respect- 


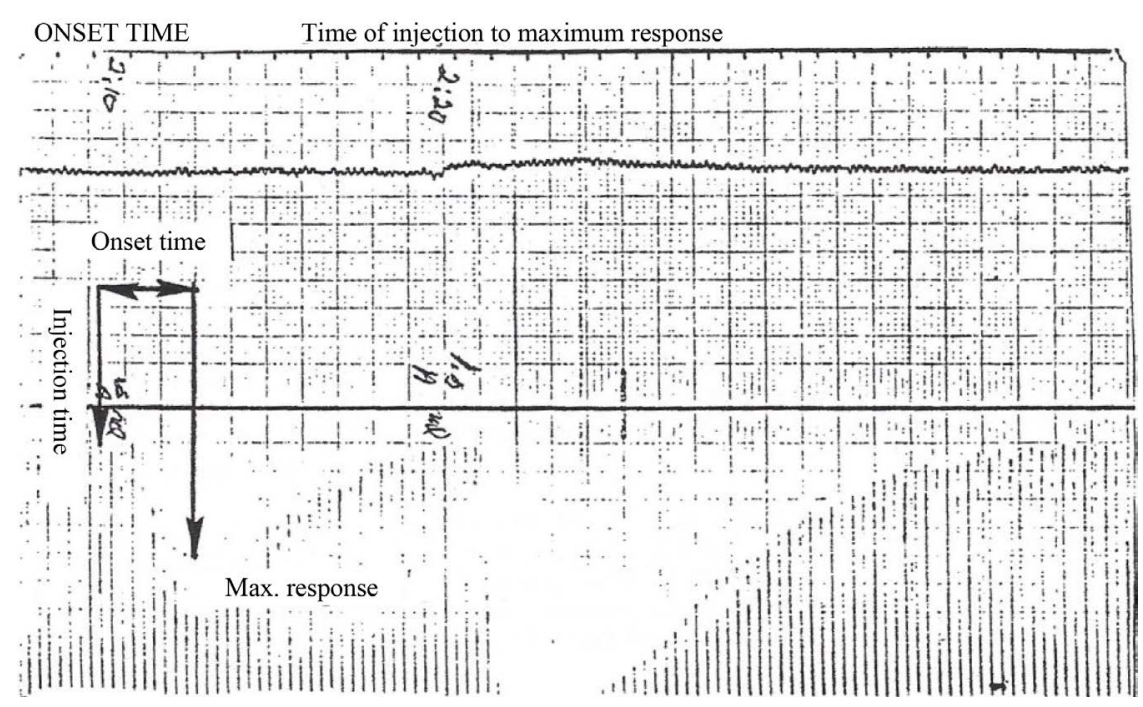

Figure 3. Recording of the train of four twitch response.

tively during the $\operatorname{Arduan}^{\mathrm{R}}$ experiments. This also contrasts with the $50 \mathrm{ug} / \mathrm{kg} / \mathrm{min}$ for Vecuronium [6] and the 30 $\mathrm{ug} / \mathrm{kg} / \mathrm{min}$ for Atracurium [12]. It appears that ORG 9426 is only one-third to one-half as potent as Vecuronium in pigs. $\operatorname{Arduan}^{\mathrm{R}}$ was 12.19 to 20.54 times more potent than ORG 9426. The fact that MHS pigs only required $66 \%$ of the infusion dose to maintain a 90 block suggests that there is a marked difference in the neuromuscular effect of ORG 9426 in MHS vs control pigs (see Figure 4). This idea is further reinforced by the marked effect of ORG 9426 on core temperature in MHS pigs, see Figure 5.

Alkalosis gave a slight increase $(0.09 \%)$ in the ORG 9426 block in control pigs.

Acidosis gave a $2.5 \%$ increase in the degree of neuromuscular block from ORG 9426. Both alkalosis and acidosis produced a decrease $(5.8 \%$ and $5.0 \%)$ respectively in MHS pigs. This opposite effect may be due to the fact that MHS pigs were more acidotic during the control period than control pigs (data not shown)

From the core temperature data table (Organon 9426), see Figure 5, it is obvious that the MHS pigs treated with a $90 \%$ blocking dose infusion of ORG 9426 exhibited a significantly greater $(\mathrm{P}<0.01)$ decrease of core temperature from $37.32^{\circ} \mathrm{C}$ down to $36.88^{\circ} \mathrm{C}$ with continued cooling during halothane and succinylcholine to a final core temperature of $36.02^{\circ} \mathrm{C}$. Rectal temperature data showed a similar decrease with an initial temperature of $37.3^{\circ} \mathrm{C}$ which dropped to $36.7^{\circ} \mathrm{C}$ and then to a final temperature of $36.2^{\circ} \mathrm{C}$. The core temperature in control pigs started at $38.24^{\circ} \mathrm{C}$ and then increased slightly to $38.36^{\circ} \mathrm{C}$ during ORG 9426 infusion. The addition of halothane and succinylcholine caused a further slight drop in core temperature to $38.02^{\circ} \mathrm{C}$. Rectal temperature in control pigs started out at $38.3^{\circ} \mathrm{C}$ and decreased to a final temperature of $37.2^{\circ} \mathrm{C}$. MHS or Control animals treated with Vecuronium and Arduan did not exhibit these significant changes in core and rectal temperatures.

These data reinforce our hypothesis that $\mathrm{MH}$ is triggered by a runaway thermogenic futile cycle at the sodium channel level [16]. The lower infusion dose of ORG 9426 required by MHS pigs to achieve a $90 \%$ block suggests that there is a neuromuscular defect which may produce a decreased number of functional sodium channels.

An interesting secondary effect is that ORG 9426 may be binding and blocking at a secondary site (allosteric site) on the sodium channel which provides protective effect at clinical dosage levels. This secondary activity at the sodium channel may be an up or down regulatory effect. ORG 9426 appears to be a down regulator whereas succinylcholine is an up regulator.

The highly lethal nature of MH may very well be explained by the defective sodium channel that discharges the $-90 \mathrm{mv}$ cell membrane charge.

The increased voltage and longer duration of mvp could lead to muscle hypertrophy via isometric contractions. This effect can be observed by the goose-step gait which these pigs have when they are walking.

ORG 9426 may be a promising drug to treat an active MH episode. That experiment has not yet been attempted. The factors that regulate sodium channel activity would be key to regulating body temperature. This would be a test of ORG 9426 in normal and MH patients to get dose response and duration 90 minutes (see Figure 6 and Figure 7). 


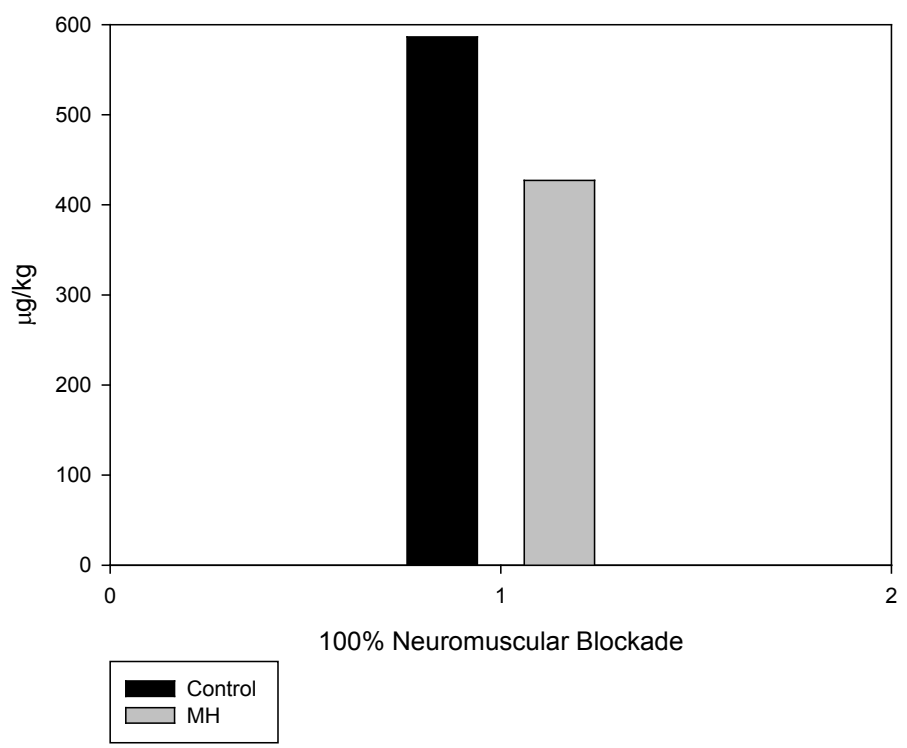

Figure 4. Graphical representation of the difference between control pigs and MHS pigs in the amount of ORG 9426 required to achieve $100 \%$ block at the myoneural junction. A linear regression analysis of the dose response to ORG 9426 in control pigs calculates that 586.31 $\mathrm{ug} / \mathrm{kg}$ would be required to produce a $100 \%$ neuromuscular blockade, this contrasts to MHS pigs that required $427.033 \mathrm{ug} / \mathrm{kg}$ which is $73 \%$ of the amount required by control pigs. This suggests that MHS pigs have markedly fewer functional sodium channels as acetylcholine receptors.

\section{Core Temperature}

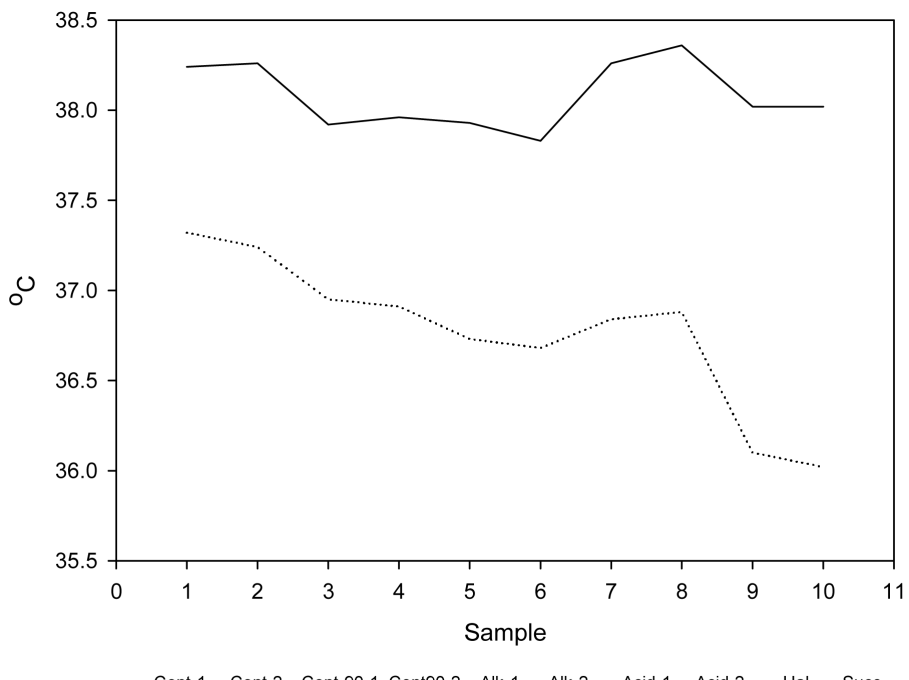

Cont-1 Cont-2 Cont-90-1 Cont90-2 Alk-1 Alk-2 Acid-1 Acid-2 Hal. Succ.

$$
\text { Control }
$$

Figure 5. Core temperatures recorded during the course of the experiments. Note that MHS pigs had a significant decrease in core temperature $(\mathrm{P}<0.01)$ during the course of the experiments. 
Dose Response Control Pigs

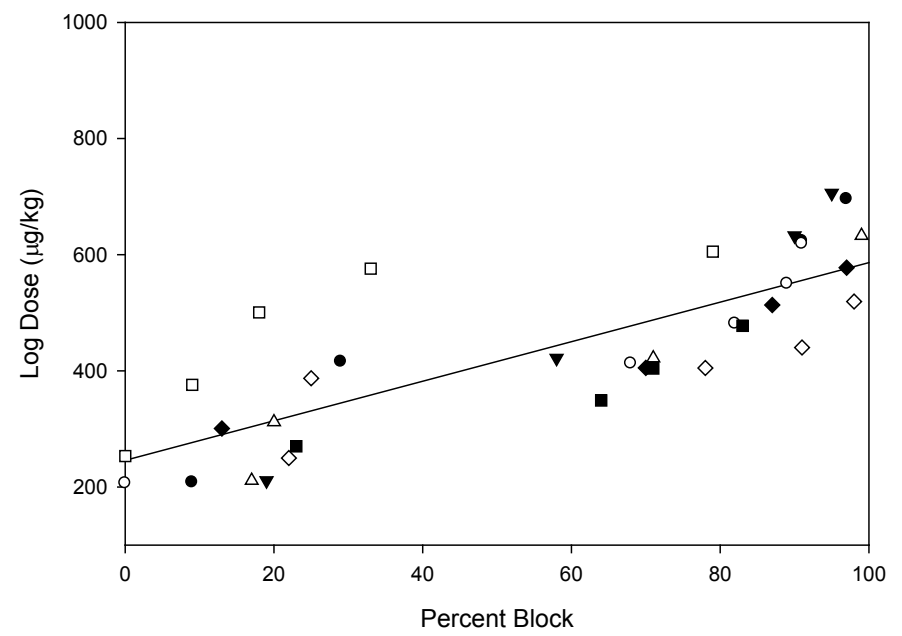

- Control $1 \%$ block vs Control 1 ug/kg

- Control $2 \%$ block vs Control $2 \mathrm{ug} / \mathrm{kg}$

- Control $3 \%$ block vs Control $3 \mathrm{ug} / \mathrm{kg}$

$\triangle$ Control $4 \%$ block vs Control $4 \mathrm{ug} / \mathrm{kg}$

- Control $5 \%$ block vs Control $5 \mathrm{ug} / \mathrm{kg}$

- Control $6 \%$ block vs Control $6 \mathrm{ug} / \mathrm{kg}$

- Control $7 \%$ block vs Control 7 ug/kg

Control $8 \%$ block vs Control $8 \mathrm{ug} / \mathrm{kg}$ Plot 1 Regr

Figure 6. Dose response in control pigs. $100 \%$ block was calculated to be at $586.31 \mathrm{ug} / \mathrm{kg}$.

Dose Response - MH Pigs

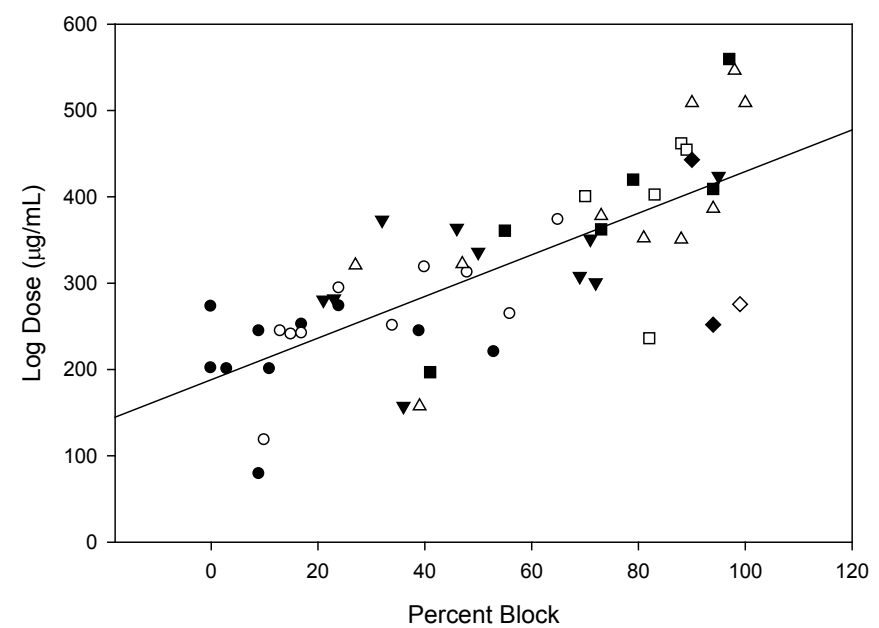

\begin{tabular}{|ll|}
\hline$\bullet$ & Percent block 1 vs Dose 1 \\
$\circ$ & Percent Block 2 vs Dose 2 \\
$\nabla$ & Percent Block 3 vs Dose 3 \\
$\Delta$ & Percent Block 4 vs Dose 4 \\
- & Percent Block 5 vs Dose 5 \\
$\square$ & Percent Block 6 vs Dose 6 \\
$\diamond$ & Percent Block 7 vs Dose 7 \\
$\diamond$ & Percent Block 8 vs Dose 8 \\
\hline & Plot 1 Regr
\end{tabular}

Figure 7. Dose response in MHS pigs. $100 \%$ block was calculated to be at $427.033 \mathrm{ug} / \mathrm{kg}$. 
Ten MHS pigs were treated with Organon 9426 during the initial infusion studies. Only one pig (MH7) developed MH immediately after the infusion during the halothane and succinylcholine challenge. The other nine pigs did not develop MH or show any sign of impending MH during the initial halothane and succinylcholine challenge. Subsequently, we modified the protocol to recover the pigs and allow them to be challenged one week later after clearing Organon 9426. We had eight animals which were recovered and challenged one week later. Seven of these animals showed the metabolic changes typical of the MH syndrome. One animal proved to be MH negative. Therefore, Organon 9426 appears to be a good candidate as a muscle relaxant which will prevent the development of the MH Syndrome. We have used Metubine Iodide, dimethyl curare, at pharmacological doses to prevent the MH Syndrome in highly MHsusceptible pigs. Organon 9426 is the first muscle relaxant we have studied to offer significant protective action at a clinical dosage.

This group of MHS pigs displays a wide variation in MH symptoms and different degrees of the acute MH syndrome. The metabolic and physiological data is consistent with our previous studies. The pigs in this group of animals were sired by an MH boar that developed MH symptoms at 12 minutes of halothane exposure who was mated to crossbred MH susceptible sows. Theoretically, the pigs would be carrying $75 \%$ of the maximum genetic dose.

Organon 9426 does not have any appreciable side effects that would inhibit its use.

There was a significant decrease in arterial and venous $\mathrm{pH}$ in MHS pigs during the infusion of ORG 9426.

Over 2000 papers have been published on ORG 9426 usage per a medline search. We will not cite those papers here.

\section{Conclusions}

- Organon 9426 is a promising drug to treat an active MH episode [17].

- Organon 9426 does not have any appreciable side-effects that will inhibit its use.

- The highly lethal nature of MH may be the result of the defective sodium channel that discharges the $-90 \mathrm{mv}$ cell membrane charge leading to rapid cell death.

- A wide variation in MH symptoms is evident in MHS pigs, so a MH pig colony must be established for meaningful experimental studies.

- The increased voltage and longer duration of myoneural voltage potential could lead to muscle hypertrophy via isometric contractions.

A secondary site (allosteric site) appears to be present on the acetyl choline receptor (sodium channel) which binds Organon 9426, thereby preventing the development of MH, even though the $90 \%$ block has been dissipated and the twitch response has returned to a $100 \%$ functional level. This effect is evident on the temperature graph and the twitch response recordings.

\section{Acknowledgements}

We thank Rita Serta, and Phool Chandra MD, Marcos Martinez and Jamie Navar for technical assistance. We thank Peter Gegg for the dose response graphs with Sigma Plot 11.0 and Dolores B Williams for typing and editing the manuscript. Organon Inc. supported part of these studies.

\section{References}

[1] Williams, C.H. (2015) Malignant Hyperthermia: Organon 9426 Was Evaluated in 10 MHS Pigs and 8 Control Pigs. Presented at EB2015 Boston, 1 April 2015, as FASEBJ 29: Abstract W109, \#1039.1.

[2] Muir, A.W., Houston, J., Green, K.L., Marshall, R.J., Bowman, W.E. and Marshall, I.G. (1989) Effects of a New Neuromuscular Blocking Agent ORG-9426 in Anesthetized Cats and Pigs and in Isolated Nerve-Muscle Preparation. Brit $J$ Physiol, 63, 400-410.

[3] Mamabe, N., Nitta, S., Nagashima, H., Duncalf, D. and Foldes F.F. (1989) The in-Vivo Neuromuscular Effects of ORG-9426 in Rats and Guinea-Pigs. Anesthesiology, 71, A774.

[4] Nagashima, H., Nguyen, H.D., Kinsey, A, Rosa, M., Hollinger, I., Goldiner, P.L. and Foldes, F.F. (1989) The Human Dose Response of ORG-9426. Anesthesiology, 71, A773.

[5] Foldes, F.F., Chaudry, I., Goldiner, P.L. and Nagashima, H. (1989) The in-Vitro Neuromuscular Effects of ORG-9426 in Rodents. Anesthesiology, 71, A772.

[6] Khuenl-Brady, K.S., Canfel, P.C., Miller, R.D., Castagnoli, K.P. and Agoston, S. (1989) Pharmacokinetics and Dispo- 
sition of ORG-9616 and ORG-9426 in the Cat. Brit J Anaesth, 62, 225P-226P.

[7] Buzello, W., Williams, C.H., Chandra, P., Watkins, M.L. and Dozier, S.E. (1985) Vecuronium and Porcine Malignant Hyperthermia. Anesthesia and Analgesia, 64, 515-519. http://dx.doi.org/10.1213/00000539-198505000-00012

[8] Hoech Jr., G.P., Roberts, J.T., Williams, C.H., Waldman, S.D., Simpson, S.T., Trim, C.M. and Brazile, J. (1980) Prevention of Porcine Malignant Hyperthermia with Metocurine. In: Thermoregulatory Mechanisms and Their Therapeutic Implications, 4th International Symposium on the Pharmacology of Thermoregulation, Oxford1979, Karger, Basel, 137-141.

[9] Williams, C.H., Dozier, S.E., Ilias, W.K. and Fulfer, R.T. (1984) Porcine Malignant Hyperthermia: Testing of Atracurium in MH Susceptible Pigs. Manuscript.

[10] Buzello, W., Williams, C.H., Chandra, P. and Watkins, M.L. (1984) Preliminary Studies on the Response of Malignant Hyperthermia Pigs to Vecuronium. Intl. Anesth. Research Soc. 58th Congress Abstracts, 67.

[11] Williams, C.H., Farias, M., Marvasti, M.A, Knight, A.B., Ekery, D.O., Daly, I.W. and Zayed, I. (1990) Malignant Hyperthermia Induction in Susceptible Swine Following Exposure to Arduan. IntI Anesth Research Soc 64th Congress, Honolulu, 10-14 March 1990.

[12] Williams, C.H., Dozier, S.E., Ilias, W.K. and Fulfer, R.T. (1985) Porcine Malignant Hyperthermia: Testing of Atracurium in MH Susceptible Pigs. Anesthesia and Analgesia, 64, 112.

[13] Williams, C.H., Hoech, G.P. and Zukaitis, M.G. (2014) A Review of the Factors Affecting the Incidence of Malignant Hyperthermia in the Greater Kansas City Area. Advances in Bioscience and Biotechnology, 5, 452-461. http://dx.doi.org/10.4236/abb.2014.55055

[14] Williams, C.H., Dozier, S.E., Ilias, W.K., Fulfer, R.T., Zukaitis, M.G. and Hoech, G.P. Diltiazem and Malignant Hyperthermia. Submitted to Anesthesia and Analgesia.

[15] Williams, C.H., Dozier, S.E. and Shanklin, M.D. (1986) Metabolic Rate in Malignant Hyperthermia Susceptible (MHS) Pigs. In: Tumbleson, M.E., Ed., Swine in Biomedical Research, Plenum, New York, 573-584.

[16] Williams, C.H. (2014) Malignant Hyperthermia: A Runaway Thermogenic Futile Cycle at the Sodium Channel Level. Advances in Bioscience and Biotechnology, 5, 197-200. http://dx.doi.org/10.4236/abb.2014.53025

[17] Williams, C.H. (2015) Malignant Hyperthermia: Organon 9426 Was Evaluated in 10 MHS Pigs and 8 Control Pigs. FASEB J, 29, 1.1039.1. 